\title{
A análise da performance nos jogos desportivos. Revisão acerca da análise do jogo
}

\author{
Júlio Garganta \\ Faculdade de Ciências do Desporto e de Educação Física, \\ Universidade do Porto
}

https://doi.org/10.5628/rpcd.01.01.57

\section{INTRODUÇÃO}

O estudo do jogo a partir da observação do comportamento dos jogadores e das equipas não é recente, tendo emergido a par com os imperativos da especialização, no âmbito da prestação desportiva. $\mathrm{Na}$ literatura, as áreas de produção de estudos realizados neste âmbito são referenciadas a partir de diferentes denominações, de entre as quais se destacam: observação do jogo (game observation), análise do jogo (match analysis) e análise notacional (notational analysis). Todavia, a expressão mais utilizada na literatura é análise do jogo (Garganta, 1997) considerando-se que engloba diferentes fases do processo, nomeadamente a observação dos acontecimentos, a notação dos dados e a sua interpretação (Franks \& Goodman, 1986; Hughes, 1996).

Dispondo hoje em dia de uma vasta gama de meios e métodos, aperfeiçoados ao longo dos anos, treinadores e investigadores procuram aceder à informação veiculada através da análise do jogo e nela procuram benefícios para aumentarem os conhecimentos acerca do jogo e melhorarem a qualidade da prestação desportiva dos jogadores e das equipas.

A informação recolhida a partir da análise do comportamento dos atletas em contextos naturais (treino e competição) é actualmente considerada uma das variáveis que mais afectam a aprendizagem e a eficácia da acção desportiva (Hughes \& Franks, 1997). Por isso, o conhecimento acerca da proficiência com que os jogadores e as equipas realizam as diferentes tarefas tem-se revelado fundamental para aferir a congruência da sua prestação em relação aos modelos de jogo e de treino preconizados.
Neste quadro de problemas, os investigadores têm procurado esclarecimentos acerca da performance diferencial dos jogadores e das equipas (Janeira, 1998), na tentativa de identificarem os factores que condicionam significativamente o rendimento desportivo e, sobretudo a forma como eles se entrecruzam para induzirem eficácia.

Em síntese, pode dizer-se que a análise da performance nos jogos desportivos tem possibilitado:

1) configurar modelos da actividade dos jogadores e das equipas;

2) identificar os traços da actividade cuja presença/ ausência se correlaciona com a eficácia de processos e a obtenção de resultados positivos;

3) promover o desenvolvimento de métodos de treino que garantam uma maior especificidade e, portanto, superior transferibilidade;

4) indiciar tendências evolutivas das diferentes modalidades desportivas.

\section{ESTADO DA ARTE}

Dos anos trinta até aos nossos dias, aumentou consideravelmente o volume de estudos de âmbito científico realizados através do recurso à observação e análise do jogo.

No Quadro 1 pode observar-se a referência a cerca de centena e meia de trabalhos realizados com recurso à análise do jogo, provenientes de diferentes quadrantes geográficos e contemplando diversos jogos desportivos. Diga-se que nele apenas estão inventariados alguns estudos e que, numa busca mais exaustiva, seria possível duplicarmos, em número, os aqui receberam menção, facto que nos permite perceber a enorme expressão que a análise 
do jogo tem vindo a assumir no quadro da investigação aplicada aos jogos desportivos.

Esta constatação é extensiva para o âmbito das actividades académicas, e pode ser atestada pelo número considerável de teses de mestrado e de doutoramento, surgidas sobretudo a partir de 1993, nas quais os respectivos autores recorreram à análise do jogo, enquanto instrumento fundamental. O interesse verificado neste domínio tem-se ainda ampliado para outros territórios, dos quais o exemplo mais flagrante é a comunicação social, cujos órgãos vêm difundindo, com insistência, alguns indicadores quantitativos, disponibilizando cifras sobre os eventos do jogo e dando forma ao que alguém, curiosamente, já chamou de "estatística popular".

Quadro 1 - Alguns estudos de análise do jogo, realizados no âmbito do treino e da competição nos JD, nos últimos setenta anos (1930 a 2000).

\begin{tabular}{|c|c|c|}
\hline DATA & AUTOR/PAÍS & MODALIDADE \\
\hline 1931 & Messersmith \& Corey (EUA) & Basquetebol \\
\hline 1932 & Messersmith \& Fay (EUA) & Futebol Americano \\
\hline 1938 & Fay \& Messersmith (EUA) & Basquetebol \\
\hline 1939 & Messersmith \& Bucher (EUA) & Basquetebol \\
\hline 1940 & Messersmith et al. (EUA) & Basquetebol \\
\hline 1942 & Messersmith (EUA) & Basquetebol \\
\hline 1944 & Messersmith (EUA) & Basquetebol (PhD) \\
\hline 1952 & Winterbottom (Inglaterra) & Futebol \\
\hline 1968 & Reep \& Benjamin (Inglaterra) & Futebol \\
\hline 1976 & Reilly \& Thomas (Inglaterra) & Futebol \\
\hline \multirow[t]{2}{*}{1977} & Sanderson \& Way (Inglaterra) & Squash \\
\hline & Schutz \& Kinsey (Inglaterra) & Squash \\
\hline \multirow[t]{2}{*}{1980} & Gayoso (Espanha) & Futebol \\
\hline & Hughes (País de Gales) & Squash \\
\hline 1981 & Wrzos (Polónia) & Futebol \\
\hline 1982 & Withers et al. (Austrália) & Futebol \\
\hline 1983 & Franks et al. (Canadá) & Futebol \\
\hline \multirow[t]{2}{*}{1984} & Espeçado \& Cruz (Espanha) & Andebol \\
\hline & Hart (Canadá) & Polo Aquático \\
\hline \multirow[t]{4}{*}{1985} & Mayhew \& Wenger (Canadá) & Futebol \\
\hline & Penner (Alemanha) & Voleibol \\
\hline & Talaga (Hungria) & Futebol \\
\hline & Van Gool \& Tilborgh (Bélgica) & Futebol \\
\hline \multirow[t]{3}{*}{1986} & Church \& Hughes (Inglaterra) & Futebol \\
\hline & Hughes \& Billingham (P. Gales) & Hóquei em Campo \\
\hline & Hughes \& Feery (País de Gales) & Basquetebol \\
\hline \multirow[t]{3}{*}{1987} & Hernandez Moreno (Espanha) & Basquetebol (PhD) \\
\hline & Martins (Portugal) & Hóquei em Patins \\
\hline & Sledziewski (Polónia) & Futebol \\
\hline \multirow[t]{7}{*}{1988} & Ali (Inglaterra) & Futebol \\
\hline & Bangsbo \& Mizuno (Dinamarca) & Futebol \\
\hline & Chervenjakov et al. (Bulgária) & Futebol \\
\hline & Docherty et al. (Canadá) & Raguebi \\
\hline & Hughes \& Charlish (P. Gales) & Futebol Americano \\
\hline & Luhtanen (Finlândia) & Futebol \\
\hline & McKenna et al. (Austrália) & Futebol Australiano \\
\hline
\end{tabular}

Ohashi et al. (Japão) Futebol

Olsen (Noruega) Futebol

Pollard et al. (Inglaterra) Futebol

Rhode \& Espersen (Dinamarca) Futebol

Van Gool et al. (Bélgica) Futebol

1989 Aguado \& Riera (Espanha) Polo Aquático

Alexander \& Boreskie (EUA) Andebol

Dufour (Bélgica)

Gréhaigne (França)

1990 Ali \& Farrally (Inglaterra)

Greco e Vieira (Brasil)

Marques (Portugal)

1991 Grosgeorge et al. (França)

Mombaerts (França)

Partridge \& Franks (Canadá)

Reilly et al. (Inglaterra)

1992 Castelo (Portugal)

Futebol

Futebol (PhD)

Futebol

Andebol

Basquetebol (MSci)

Basquetebol

Futebol

Futebol

Futebol

Futebol (PhD)

D' Ottavio \& Tranquilli (Itália) Futebol

Doggart et al. (País de Gales) Futebol Gaélico

Eom \& Schutz (Canadá) Voleibol

Erdman \& Dargiewicz (Polónia) Andebol

Handford \& Smith (Voleibol) Voleibol

Loy (Alemanha) Futebol

Smith \& Hughes (País de Gales) Polo Aquático

Stanhope \& Hughes (P. Gales) Raguebi

Wilkins et al. (Canadá)

Winkler (Alemanha)

Hóquei sobre o gelo

Futebol

1993 Anton \& Romance (França) Andebol

Bishovets et al. (Rússia) Futebol

Claudino (Portugal) Futebol (MSci)

Gerish \& Reichelt (Alemanha) Futebol

Jinshan et al. (Japão) Futebol

Luhtanen (Finlândia) Futebol

Moutinho (Portugal) Voleibol (MSci)

Rebelo (Portugal)

Yamanaka et al. (Japão)

1994 Czerwinski (Polónia)

Janeira (Portugal)

Lloret (Espanha)

Lothian \& Farraly (Inglaterra)

McGarry \& Franks (Canadá)

Sarmento (Portugal)

1995 Bacconi \& Marella (Itália)

Barreto (Portugal)

Bezerra (Portugal)

Fröner (Alemanha)

Luhtanen et al. (Finlândia)

Melli (Itália)

Richers (Inglaterra)

Silva (Portugal)

1996 Borges (Portugal)

Garbarino (França)

Futebol (MSci)

Futebol

Andebol

Basquetebol

Polo Aquático $(\mathrm{PhD})$

Hóquei em Campo

Squash

Polo Aquático $(\mathrm{PhD})$

Futebol

Basquetebol (PhD)

Futebol (MSci)

Voleibol

Futebol

Futebol

Ténis

Futebol

Andebol (MSci)

Garganta \& Gonçalves (Portugal) Futebol

Hernandez Mendo (Espanha) Vários (PhD)

Larson et al. (Noruega)

Liddle et al. (Inglaterra)

Loy (Alemanha)

Mendes (Portugal)

Oliveira (Portugal)

Safon-Tria (Espanha)

Sampedro (Espanha)

1997 Garganta (Portugal)
Futebol

Badminton

Futebol

Basquetebol (MSci)

Andebol (MSci)

Futebol

Futsal (PhD)

Futebol (PhD) 


$\begin{array}{lll} & \text { Garganta et al. (Portugal) } & \text { Futebol } \\ \text { Kingman \& Dyson (Inglaterra) } & \text { Hóquei em Patins } \\ \text { Maçãs (Portugal) } & \text { Futebol (MSci) } \\ \text { Olsen \& Larsen (Noruega) } & \text { Futebol } \\ \text { Sampaio (Portugal) } & \text { Basquetebol (MSci) } \\ \text { Vaslin et al. (França) } & \text { Voleibol } \\ \text { Verlinden (Bélgica) } & \text { Futebol } \\ \text { Xie (China) } & \text { Basquetebol } \\ 1998 & \text { Fraújo (Portugal) } & \text { Futebol (MSci) } \\ \text { Ardá (Espanha) } & \text { Futebol (MSci) } \\ \text { Ferreira da Silva (Portugal) } & \text { Andebol (MSci) } \\ \text { Leitão (Portugal) } & \text { Futebol (MSci) } \\ \text { Silva (Portugal) } & \text { Futebol (PhD) } \\ \text { Vales (Espanha) } & \text { Andebol (MSci) } \\ \text { Barbosa (Portugal) } & \text { Futebol } \\ \text { D'Ottavio \& Castagna (Itália) } & \text { Andebol (MSci) } \\ \text { Fonseca (Portugal) } & \text { Ténis (PhD) } \\ \text { Gorospe (Espanha) } & \text { Squash } \\ \text { McGarry et al. (Canadá) } & \text { Andebol (MSci) } \\ \text { Mortágua (Portugal) } & \text { Futebol (MSci) } \\ \text { Neves da Silva (Portugal) } & \text { Andebol (MSci) } \\ \text { Santos (Portugal) } & \text { Polo Aquático (PhD) } \\ \text { Argudo (Espanha) } & \text { Basquetebol (PhD) } \\ \text { Castellano (Espanha) } & \\ \text { Hernandez Mendo \& Anguera } & \\ \text { (Espanha) } & \text { Hóquei em Patins } \\ \text { Lago (Espanha) } & \text { Vários (PhD) } \\ \text { McErlean et al. (Irlanda) } & \text { Futebol Gaélico } \\ \text { Moutinho (Portugal) } & \text { Voleibol (PhD) } \\ \text { Ortega (Espanha) } & \text { Futebol } \\ \text { Silva (Portugal) } & \text { Andebol (MSci) } \\ \text { Sousa (Portugal) } & \text { Voleibol (MSci) } \\ & \\ & \end{array}$

MSci - Dissertações de Mestrado;

PhD - Dissertações de Doutoramento

Partindo do princípio que as incidências do jogo obedecem a uma lógica interna particular (Teodorescu, 1985; Hernandez-Pérez, 1994; Garganta, 1997), vários autores têm procurado perceber os constrangimentos que caracterizam os diferentes JD, no sentido de modelar um quadro de exigências que se constitua como referência fundamental para o treino (Reep \& Benjamin, 1968; Gréhaigne, 1989; Dufour \& Verlinden, 1994; Garganta, 1997; McGarry et al., 1999; Castellano, 2000; Moutinho, 2000).

Do conteúdo da literatura, ressalta que os investigadores têm recorrido a diversas categorias de observação e a distintos níveis de análise. Com o intuito de proceder à caracterização da actividade desenvolvida pelos jogadores e as equipas durante as partidas, os especialistas focalizaram, inicialmente, os seus estudos na actividade física imposta aos jogadores, nomeadamente no que respeita às distâncias percorridas.

Um dos primeiros, senão o primeiro, dos estudos que se conhecem no âmbito da análise do jogo nos JD, foi realizado pelo norte-americano Lloyd Lowell Messersmith, com a colaboração de S. Corey, em 1931 (Messersmiyh \& Corey, 1931), no qual os autores dão a conhecer um método para determinar as distâncias percorridas por um jogador de Basquetebol. No ano seguinte surge um outro estudo, também liderado por Messersmith, com a colaboração de Fay (Messersmith \& Fay, 1932), no qual os autores aplicam o método já desenvolvido para o Basquetebol, para determinar a distância percorrida por jogadores de Futebol Americano. Refira-se, a título de exemplo, que entre 1930 e 1944 podemos encontrar mais de uma dezena de estudos, realizados nos Estados Unidos da América, orientados para a determinação das distâncias percorridas por jogadores de Basquetebol (Lyons, 1998).

O direccionamento das linhas de investigação foi ampliando o seu campo de análise, evoluindo para a denominada análise do tempo-movimento, através da qual se procura identificar, detalhadamente, o número, tipo e frequência das tarefas motoras realizadas pelos jogadores ao longo do jogo. Para além do paradigmático trabalho de Reilly \& Thomas (1976), levado a cabo no âmbito do Futebol, outros estudos têm sido realizados nesta modalidade, e.g. Withers et al. (1982), Mayhew \& Wenger (1985), Ohashi et al. (1988), D'Ottavio \&Tranquilli, 1992) e Rebelo (1993). Na mesma linha, várias pesquisas vêm sendo realizadas no Andebol (Alexander \& Boreskie, 1989; Borges, 1996), no Badminton (Liddle et al., 1996), no Basquetebol (Janeira, 1994; Sampaio, 1997), no Hóquei em Campo (Lothian \& Farraly, 1994), no Hóquei no Gelo (Wilkins et al., 1992), no Raguebi (Docherty et al., 1988) e no Ténis (Richers, 1995), entre outras.

A análise das habilidades técnicas tem sido outro dos campos explorados na análise do jogo (Dufour, 1989; Partridge, \& Franks, 1991; Mesquita, 1998; Hoff \& Haaland, 1999).

Contudo, a inépcia das conclusões decorrentes dos resultados provenientes de estudos quantitativos, centrados nas acções técnicas individuais, levaram 
os analistas a questionar a pouca relevância contextual dos dados recolhidos e a duvidar da sua pertinência e utilidade.

Esta questão fez sobressair a necessidade de se considerar a dimensão técnica em relação com os condicionalismos tácticos, já que aquela não pode perfilar per se os traços dominantes do jogo (Gréhaigne, 1989; Dufour, 1993; Garganta, 1997). A consciência de que a expressão táctica assume uma importância capital nos JD, fez com que a partir da segunda metade da década de oitenta, a identificação de regularidades reveladas pelos jogadores e pelas equipas, no quadro das acções colectivas, tivesse despontado enquanto nova tendência de investigação (Gréhaigne, 1989; Lloret, 1994; Hernandez Mendo, 1996; Garganta, 1997) Neste âmbito, os analistas têm procurado coligir e confrontar dados relativos aos comportamentos expressos no jogo, no sentido de tipificarem as acções que se associam à eficácia dos jogadores e das equipas. Esta procura aponta três vias preferenciais:

1) uma que consiste em reunir e caracterizar blocos quantitativos de dados;

2) outra mais centrada na dimensão qualitativa dos comportamentos, e na qual o aspecto quantitativo funciona como suporte à caracterização das acções, de acordo com a efectividade destas no jogo;

3) uma terceira, voltada para a modelação do jogo, a partir da observação de variáveis técnicas e tácticas e da análise da sua covariação.

Sabe-se que as equipas podem variar os seu padrões de jogo de acordo com as características da oposição oferecida pelo adversário (Hughes, 1996). Todavia, poucos investigadores têm tomado em conta este aspecto (Gréhaigne, 1989; Garganta, 1997).

A necessidade de interpretar os dados recolhidos em função das características específicas das partidas, tem levado os analistas a focalizarem cada vez mais a sua atenção na relevância contextual dos comportamentos dos participantes, o que justifica o estudo da organização do jogo das equipas em confronto (Hughes et al., 1988; Gréhaigne, 1989; Gréhaigne \& Bouthier, 1994; Garganta, 1997). Uma das tendências que se perfilam prende-se com a detecção de padrões de jogo, a partir das acções de jogo mais representativas, ou críticas, com o intuito de perceber os factores que induzem perturbação ou desequilíbrio no balanço ataque/defesa. Neste sentido, os analistas procuram detectar e interpretar a permanência e/ou ausência de traços comportamentais na variabilidade de acções de jogo (McGarry \& Franks, 1996).

\section{EVOLUÇÃO METODOLÓGICA E INSTRUMENTAL DA ANÁLISE DO JOGO}

O processo de recolha, colecção, tratamento e análise dos dados obtidos a partir da observação do jogo, assume-se como um aspecto cada vez mais importante na procura da optimização do rendimento dos jogadores e das equipas. Neste sentido, através dos denominados sistemas de observação, os especialistas procuram desenvolver instrumentos e métodos que lhes permitam reunir informação substantiva sobre as partidas.

O processo de observação e análise do jogo tem experimentado uma evolução evidente ao nível dos sistemas utilizados, a qual se tem processado por etapas, em cada uma das quais o sistema desenvolvido surge no sentido de aperfeiçoar os precedentes.

Nos primórdios as observações realizavam-se ao vivo, eram assistemáticas e subjectivas, impressionistas. Os registos dos comportamentos dos atletas e das equipas eram realizados a partir da técnica denominada "papel e lápis", com recurso à notação manual.

Embora esta fase inicial se tivesse pautado por um forte pendor acumulacionista, à vontade de coligir uma enorme quantidade de dados parciais, sucedeu a de elaborar instrumentos de observação. Mais recentemente, a profissionalização das práticas de alta competição, os meios financeiros disponíveis e a utilização do desporto como terreno de aplicação da tecnologia suscitaram novas investigações, o que conduziu a que a informática, ao substituir as técnicas manuais, tenha permitido uma maior e mais rápida recolha de informação, bem como um acesso mais rápido aos dados disponíveis (Grosgeorge, 1990). $\mathrm{Na}$ medida em que as técnicas e os sistemas de observação diferem segundo as disciplinas desportivas (Franks \& Goodman, 1986; Dufour, 1989; Grosgeorge et al., 1991), para analisar os 
comportamentos nos JD torna-se necessário desenvolver métodos de recolha e de análise específicos.

Com o advento dos meios informáticos, os analistas do jogo têm assistido ao alargamento progressivo do espectro de possibilidades instrumentais colocadas à sua disposição. Nos anos mais recentes tem-se verificado uma aposta clara na utilização de metodologias com recurso a instrumentos cada vez mais sofisticados, e.g. a análise do jogo apoiada por computador, os quais pelas suas elevadas capacidades de registo e memorização tendem a constituir-se como um equipamento importante para o treinador e para o investigador (Franks, 1987; Grosgeorge, 1990; Dufour, 1993).

Duma forma sintética é possível estabelecer uma cronologia relativa ao desenvolvimento de tais meios:

1. Sistemas de notação manual com recurso à designada técnica de papel e lápis (Reep \& Benjamin, 1968).

2. Combinação de notação manual com relato oral para ditafone (Reilly \& Thomas, 1976).

3. Utilização do computador a posteriori da observação, para registo, armazenamento e tratamento dos dados (Ali, 1988).

4. Utilização do computador para registo dos dados em simultâneo com a observação, em directo ou em diferido (Dufour, 1989).

5. A introdução de dados no computador através do reconhecimento de categorias veiculadas pela voz (voice-over) é um sistema que tem vindo a ser desenvolvido (Taylor \& Hughes, 1988) e que, segundo Hughes (1993), no futuro poderá facilitar a recolha de dados, mesmo a não especialistas. A utilização do CD-Rom, para aumentar a capacidade de memória para armazenamento dos dados, é outra das possibilidades a explorar (Hughes, 1996).

6. O sistema mais evoluído que se conhece dá pelo nome de AMISCO e permite digitalizar semiautomaticamente as acções realizadas pelos jogadores e pelas equipas, seguindo o jogo em tempo real e visualizando todo o terreno de jogo. Com base na utilização de 8, 10 ou 12 cameras fixas é possível monitorizar e registar toda a actividade dos jogadores.
Quando se utilizam computadores, as categorias e os indicadores seleccionados para a entrada de informação, ou input, procuram responder a quatro questões:

(i) quem executa a acção?

ii) qual - como e de que tipo - é a acção realizada?

(iii) onde se realiza a acção?

(iv) quando é realizada a acção?

O teclado convencional do computador (QWERTY) raramente preenche os requisitos necessários a um rápido e eficaz input dos dados. Por isso, em alternativa, tem sido substituído por teclados especialmente concebidos, onde figuram as categorias - concept keyboard (Church \& Hughes, 1986) e por uma mesa de digitalização - digital panel, na qual se assinala a espacialização das acções (Dufour, 1991). Nalguns sistemas, mesa de digitalização e teclado constituem uma única peça informática denominada touchpad (Hughes et al., 1988; Partridge et al., 1993). Noutros, as células com as categorias a digitar figuram directamente sobre a representação gráfica do terreno de jogo. Este tipo de aparelho designa-se por playpad (Partridge \& Franks, 1989).

\section{TENDÊNCIAS DA ANÁLISE DO JOGO}

Nos últimos anos tem-se assistido a uma proliferação de alternativas para analisar a prestação dos desportistas e das equipas, consubstanciada na disparidade de indicadores e de procedimentos adoptados para tal efeito.

Nos estudos produzidos no âmbito da análise dos JD, constata-se que os autores vêm recorrendo a metodologias diversas, como a análise sequencial (Hernandéz Mendo, 1996; Ardá, 1998), a análise de unidades tácticas e de clusters (Garganta, 1997; Sousa, 2000), a análise de coordenadas polares (Gorospe, 1999) e o estudo das unidades de competição (Alvaro et al., 1995).

Cada vez mais se procura, a partir da análise de bases de dados, configurar modelos de jogo (Bishovets et al., 1993; McGarry \& Franks, 1995a) que permitam definir asserções preditivas acerca da táctica eficaz - 
winning tactic (McGarry \& Franks, 1995b).

Todavia, este entendimento tem gerado alguma controvérsia, questionando-se os métodos estatísticos utilizados (Hughes, 1996) e a sua aplicabilidade face à aleatoriedade e imprevisibilidade dos comportamentos que caracterizam os JD. Deste modo, alguns investigadores têm vindo a abandonar os modelos estocásticos, em que se utiliza o quiquadrado enquanto teste estatístico (Kenyon \& Schutz, 1970), em favor dos modelos log-lineares (Eom \& Schutz, 1992).

Diga-se, contudo, que os problemas relacionados com a modelação do jogo transcendem largamente a questão dos métodos estatísticos. Como evidencia Dufour (1991), as dificuldades encontradas na definição de categorias de observação, bem como na construção de um algoritmo adequado, têm entravado um melhor entendimento do jogo, dificultando uma célere evolução dos JD. Ao nível do entendimento da organização do jogo, gerou-se, durante alguns anos, um impasse metodológico importante, devido ao recurso a métodos exclusivamente algorítmicos, em detrimento de métodos heurísticos (Gréhaigne, 1989). Nos JD, o algoritmo, para ser exaustivo, deveria ter em conta todas as alternativas possíveis, o que colide com a natureza das numerosas e diversas situações que ocorrem num jogo. Neste sentido, os procedimentos heurísticos, porque não preconizam uma tal exaustividade, parecem revelar-se mais apropriados ao carácter não totalmente previsível do jogo (Gréhaigne, 1992).

No entanto, ambos os procedimentos, algorítmicos e heurísticos, são importantes na codificação e interpretação das acções realizadas pelos jogadores e pelas equipas (Garganta, 1997). O problema colocase, sobretudo, ao nível da sua complementaridade e compatibilização.

Os procedimentos algorítmicos, porque comportam a identificação dos estados cruciais para a selecção das operações, são úteis na sistematização e ordenamento dos descritores, desde que não provoquem um "fechamento" do sistema de observação. Os procedimentos heurísticos, porque relacionados com os atributos do pensamento criador e da descoberta, revelam-se importantes nas fases de selecção dos descritores das acções de jogo (categorias e indicadores) e da sua reformulação. Nesta medida, os sistemas devem ter a abertura suficiente para permitirem, sempre que necessário, uma reformulação de categorias e indicadores, no sentido de garantir o seu permanente aperfeiçoamento e adequação.

\subsection{Dados ou informação?}

$\mathrm{Na}$ sua essência, o processo de treino visa induzir modificações observáveis no comportamento dos praticantes (Hughes \& Franks, 1997), no sentido em que as mesmas adquiram o máximo de transfere positivo para os contextos de competição.

$\mathrm{O}$ jogo, enquanto confronto de duas entidades, com objectivos antagónicos, emerge do entrelaçamento das acções desenvolvidas pelos jogadores/equipas. A maior ou menor adequação de uma determinada acção face ao contexto que a suscita, decorre de lógicas intimamente ligadas à forma como os actores (jogadores) apreendem as linhas de força do jogo e ao nível de conhecimento táctico (declarativo e processual) que os mesmos denotam.

Não é de admirar, portanto, que a solução encontrada por um jogador, para resolver uma situação de jogo, comporte quase sempre uma margem considerável de subjectividade. Esta é extensiva a todos os observadores e aumenta com o número e a variabilidade dos eventos de jogo, pelo que a análise sistemática do jogo apenas é fiável se os seus propósitos estiverem claramente definidos. Não obstante a análise do jogo possa disponibilizar informação importante, permanece ainda uma certa resistência à sua utilização, baseada na visão tradicional de que os treinadores experientes podem observar um jogo sem qualquer sistema de apoio à observação, e que retêm com precisão os elementos críticos do jogo (Franks \& McGarry 1996).

Estudos realizados pelos canadianos Franks \& Miller, em 1986, demonstraram que treinadores de Futebol, quando instados a descrever os acontecimentos ocorridos em 45 minutos de uma partida de Futebol obtiveram valores inferiores a $45 \%$ de respostas certas.

Em 1993, Franks realizou um estudo em que comparou a apreciação de treinadores experientes com treinadores principiantes, face à performance realizada por atletas. Os treinadores experientes 
produziram mais falsas respostas do que os novatos e detectaram diferenças onde elas não existiam. Para além disso, mostraram-se mais confiantes, mesmo quando errados nas suas apreciações.

Estes estudos atestam que a observação é tão necessária quanto falível, tornando-se imprescindível conhecer o seu alcance e os seus limites. Comprovam também que a memória humana é limitada, sendo praticamente impossível relembrar todos os acontecimentos que ocorrem durante uma partida (Hughes \& Franks, 1997) e menos ainda as ocorrências de vários jogos, ao longo de um ou vários campeonatos.

Sabendo-se que o processamento da informação visual é extremamente complexo e que os treinadores estão submetidos à forte pressão das emoções e à parcialidade, como alternativa à observação casual e subjectiva, tem-se sugerido e utilizado a observação sistemática e objectiva, a qual tem permitido recolher um número significativo de dados sobre o jogo, nomeadamente através de sistemas computadorizados.

Mas, há que estar atento ao objectivo paradoxal que aqui se perfila, pois trata-se de objectivar a subjectividade. A intenção última é identificar os elementos críticos do sucesso na prestação desportiva, traduzindo "dados" em informação fiável e útil.

Percorrendo vários estudos que se debruçam sobre a observação e análise do jogo nos JD, verifica-se que os sistemas de observação utilizados têm privilegiado, na sua maioria, a análise descontextualizada das acções do jogador, o produto das acções ou comportamentos, a dimensão quantitativa das acções e as situações que originam golo ou ponto.

Para treinadores e investigadores, as análises que salientam o comportamento da equipa e dos jogadores, através da identificação das regularidades e variações das acções de jogo, afiguram-se claramente mais profícuas do que a exaustividade de elementos quantitativos, relativos a acções individuais e não contextualizadas.

Face às necessidades e particularidades dos JD, justifica-se a construção de sistemas elaborados a partir de categorias integrativas, configuradas para caracterizar (Garganta, 1997): (1) a organização do jogo a partir das características das sequências de acções (unidades tácticas) das equipas em confronto; (2) os tipos de sequências que geram acções positivas; (3) as situações que induzam ruptura ou perturbação no balanço ofensivo e defensivo das equipas que se defrontam; (4) as quantidades da qualidade das acções de jogo.

\subsection{Encontrar primeiro; procurar depois!}

No domínio particular da análise do jogo, tem-se verificado que, não raramente, os sistemas de observação e registo perdem eficácia pelo facto do caudal de dados obtido se afigurar confuso (Gerish \& Reichelt, 1993), porquanto constitui material disperso e retalhado. Quer isto dizer que, não obstante o recurso a meios sofisticados, a proliferação de bases de dados não garante, por si só, o acesso a informação pertinente para treinadores e investigadores. Para contornar este problema tornase imprescindível dar um sentido ao dados recolhidos, explorando-os de forma a garantirem o acesso à informação considerada importante (Garganta, 1997).

Assim, a viabilização duma observação e análise do jogo ajustadas impõe, para além dos instrumentos tecnológicos, a definição clara de instrumentos conceptuais (modelos) que balizem a elaboração e aplicação de metodologias congruentes com a natureza do jogo (Pinto \& Garganta, 1989). Habitualmente diz-se que para encontrar algo, há que procurá-lo. No contexto da observação e análise do jogo, a lógica é inversa, ou seja, primeiro encontra-se (configura-se) as categorias e os indicadores e só depois se procura e se afere as suas formas de expressão no jogo. Apenas deste modo os sistemas computadorizados podem constituir-se como aliados na resolução eficaz de problemas. As condições instáveis e aleatórias em que ocorrem os JD, embora confiram originalidade e interesse às situações, tornam mais delicada a tarefa do observador e do experimentador.

Nos desportos individuais, desde há muito que a observação incide preferencialmente nos aspectos técnicos da execução. Nestas modalidades, as análises biomecânicas podem bastar para informar com exactidão sobre o comportamento do atleta e, assim, fornecer dados suficientes que permitam 
estabelecer um plano de treino ou detectar talentos. Pelo contrário, nos JD as capacidades dos atletas são condicionadas fundamentalmente pelas imposições do meio, isto é, pelas sucessivas configurações que o jogo vai experimentando e, por tal motivo, a observação de todos os jogadores em movimento torna-se extremamente complexa. Para além disso, a interdependência dos comportamentos constitui um obstáculo difícil de ultrapassar.

A metodologia observacional (Anguera, 1999) e a análise de dados abrem territórios fecundos de investigação no domínio das Ciências do Desporto, nomeadamente no que respeita ao entendimento das condições que concorrem para o sucesso nos jogos desportivos. Todavia, para que tal se concretize, importa passar de uma observação passiva, portanto sem problema definido, com baixo controlo externo e carente de sistematização, para uma observação activa, i.e., sistematizada, balizada por um problema e obedecendo a um controlo externo (Anguera et al., 2000).

\section{CONSIDERAÇÕES FINAIS}

A parafernália tecnológica não aumenta, necessariamente, a eficácia da observação nem os conhecimentos sobre uma determinada realidade. Mas a tecnologia pode aumentar significativamente a qualidade e a celeridade do processo de observação e análise desde de que dela se faça o uso adequado. Não desdenhando do progresso, entendemos que o frenesim da sofisticação tecnológica, não raramente com objectivos de marketing científico, pode conduzir a que os analistas sejam cada vez mais especialistas de informática e cada vez menos especialistas do jogo. A suceder, este facto representa a desvirtuação do objecto de estudo (o jogo e o treino) e a alienação do móbil da investigação, i.e., o conhecimento da lógica que governa a actividade desportiva nestes contextos particulares.

$\mathrm{Na}$ ausência de um modelo teórico que garanta o enquadramento e a interpretação dos dados obtidos, deparamos com uma massa de números com fraco poder informativo (Gréhaigne, 1992). Impõe-se, assim, que à sofisticação tecnológica dos sistemas de observação, corresponda o progressivo refinamento e extensão das categorias que os integram, no sentido de aumentar o seu potencial descritivo relativamente às acções de jogo consideradas mais representativas (Garganta, 1997).

Pelo que foi referido, parece curial manter no horizonte a máxima de Poincaré: a ciência é feita de dados, como uma casa é feita de pedras. Mas um conjunto de dados não é ciência, tal como um conjunto de pedras não é uma casa.

\section{REFERÊNCIAS}

Por imperativos de gestão dos espaços de publicação, o elenco de menções bibliográficas não é aqui apresentado, dado o elevado número de referências que integra (150). Os interessados poderão solicitá-las ao autor, cujo endereço electrónico é: jgargant@fcdef.up.pt 